\title{
O Papel da Consciência Fonológica e da Nomeação Seriada Rápida na Alfabetização de Adultos
}

\author{
The Role of Phonological Awareness and Rapid Serial Naming \\ in Adult Literacy Acquisition
}

\author{
Marcela Fulanete Corrêa \& Cláudia Cardoso-Martins* \\ Universidade Federal de Minas Gerais, Belo Horizonte, Brasil
}

\begin{abstract}
Resumo
Este estudo investigou a contribuição da consciência fonológica e da nomeação seriada rápida para a habilidade de leitura e escrita em uma amostra de 72 adultos inscritos em um programa de alfabetização. Os resultados questionam a hipótese de que, em ortografias caracterizadas por relações letra-som consistentes, a nomeação seriada rápida é mais importante do que a consciência fonológica para a alfabetização. No presente estudo, a consciência fonológica contribuiu tanto quanto a nomeação seriada rápida para a habilidade de ler palavras e mais do que a nomeação seriada rápida para a habilidade de escrever palavras.
\end{abstract}

Palavras-chave: Processamento fonológico, leitura, escrita, alfabetização de adultos.

\begin{abstract}
This study investigated the contribution of phonological awareness and rapid serial naming skills to reading and spelling ability in a sample of 72 Brazilian adults enrolled in a literacy acquisition program. Results questioned the hypothesis that rapid serial naming skills are more important for literacy acquisition than phonological awareness in orthographies characterized by consistent letter-sound relations. In the present study, phonological awareness contributed as much as rapid serial naming to reading ability, but more than rapid serial naming to spelling ability.

Keywords: Phonological processing, reading, spelling, adult literacy.
\end{abstract}

Desde o trabalho pioneiro de Morais, Cary, Alegria e Bertelson (1979), vários estudiosos tem se interessado em investigar a relação entre o processamento fonológico e a habilidade de leitura de adultos com pouca ou nenhuma escolaridade. O presente estudo também é fruto desse interesse. Em particular, o estudo avalia a contribuição de dois componentes do processamento fonológico - a consciência fonológica e a nomeação seriada rápida - para a habilidade de leitura e escrita de jovens e adultos com baixos níveis de escolaridade. Conforme descrito a seguir, este é um dos primeiros estudos a investigar a habilidade de escrita de adultos com pouca escolaridade e, ao que tudo indica, o primeiro a investigar a contribuição de

* Endereço para correspondência: Departamento de Psicologia, Faculdade de Filosofia e Ciências Humanas, Universidade Federal de Minas Gerais, Av. Antônio Carlos, 6627, Pampulha, Belo Horizonte, MG, Brasil 31270-901. E-mail: cardosomartins.c@gmail.com A realização deste estudo foi possível graças a um financiamento de pesquisa do Conselho Nacional de Desenvolvimento Científico e Tecnológico (CNPq) e da Fundação de Amparo à Pesquisa do Estado de Minas Gerais (FAPEMIG) à segunda autora. As autoras agradecem a colaboração dos jovens e adultos que participaram do estudo. variações na nomeação seriada rápida para a habilidade de leitura e escrita nessa população.

A consciência fonológica, isto é, a habilidade de identificar, isolar ou manipular os sons da fala, é, sem dúvida, o componente do processamento fonológico que tem sido mais investigado em relação à aquisição da leitura e da escrita. Os resultados de estudos com crianças mostram, de maneira inequívoca, que a consciência fonológica contribui estreitamente para o sucesso na alfabetização, independentemente da ortografia em que a criança aprende a ler (e.g. Bryant \& Bradley, 1987; Caravolas, Volin, \& Hulme, 2005; Cardoso-Martins, 1995; Castles \& Coltheart, 2004; Ziegler et al., 2010). Resultados semelhantes têm sido obtidos em estudos com adultos com pouca ou nenhuma escolaridade, sugerindo que o papel desempenhado pela consciência fonológica na alfabetização também independe da idade ou do nível de desenvolvimento do aprendiz (e.g., Binder \& Borecki, 2008; Durgunoglu \& Öney, 2002; Loureiro et al., 2004; Lukatela, Carello, Shankweiler, \& Liberman, 1995; Mellard, Fall, \& Woods, 2010; Mota \& Castro, 2007).

A despeito do enorme interesse que a nomeação seriada rápida tem despertado entre os estudiosos da alfabetização, não encontramos nenhum estudo que tenha 
investigado a contribuição dessa variável para a habilidade de leitura e escrita de jovens e adultos com pouca escolaridade. A nomeação seriada rápida é frequentemente avaliada através de tarefas de nomeação de estímulos, nas quais os participantes são solicitados a nomear tão rapidamente quanto possível séries de estímulos visuais familiares, como figuras de objetos, cores, letras ou números.

Tradicionalmente, a nomeação seriada rápida tem sido classificada como um componente do processamento fonológico. De acordo com Wagner e Torgesen (1987), a razão para isso deve-se ao fato dessa habilidade envolver o acesso à representação fonológica das palavras na memória de longo prazo (Torgesen, Wagner, Rashotte, Burgess, \& Hecht, 1997; Wagner, Torgesen, Laughon, Simmons, \& Rashotte, 1993). Essa classificação, contudo, não é consensual. Para Wolf e Bowers (1999), por exemplo, embora a nomeação seriada rápida envolva processos fonológicos, processos de natureza perceptual, lexical e motora são também necessários para a execução da tarefa. Na opinião dessas autoras, é a habilidade de integração desses processos, através de mecanismos temporais precisos, a verdadeira responsável pela relação entre a nomeação seriada rápida e a habilidade de leitura e escrita.

Há, de fato, evidência de que a nomeação seriada rápida e a consciência fonológica contribuem de forma distinta e independente para as habilidades de leitura de crianças em idade escolar (e.g., Cardoso-Martins \& Pennington, 2004; Manis, Doi, \& Bhadha, 2000; Powell, Stainthorp, Stuart, Garwood, \& Quinlan, 2007). Especificamente, os resultados desses estudos sugerem que a consciência fonológica correlaciona-se mais fortemente com a codificação fonológica, isto é, a habilidade de ler através da tradução das letras em seus sons correspondentes, ao passo que a nomeação seriada rápida está mais relacionada com a aquisição da codificação ortográfica, ou seja, da habilidade de formar, armazenar e acessar representações da grafia das palavras no léxico mental.

Por exemplo, Manis et al. (2000) avaliaram a relação entre, por um lado, a nomeação seriada rápida e a consciência fonológica e, por outro lado, a habilidade de leitura, em um grupo de 85 crianças americanas com idade entre 7 e 8 anos. A habilidade de ler foi avaliada através de uma tarefa de leitura de pseudopalavras e uma tarefa de leitura de palavras irregulares. Pseudopalavras são palavras inventadas e, portanto, só podem ser lidas através da tradução das letras em seus sons correspondentes. Palavras irregulares são aquelas que violam as regras de correspondência letra-som. Como resultado, a pronúncia dessas palavras pressupõe a recuperação de códigos fonológicos diretamente do léxico mental. Os resultados indicaram que a contribuição da nomeação seriada rápida foi mais forte para a leitura de palavras irregulares, ao passo que a consciência fonológica correlacionou-se mais estreitamente com a leitura de pseudopalavras. Resul- tados semelhantes têm sido encontrados entre crianças aprendendo a ler em outras línguas. De maneira interessante, alguns pesquisadores (Babayigit \& Stainthorp, 2011; Wimmer, 1993; Wimmer \& Mayringer, 2002) têm sugerido que, entre os aprendizes de ortografias caracterizadas por relações letra-som mais regulares do que a ortografia inglesa, a nomeação seriada rápida contribui mais para a habilidade de leitura e escrita do que a consciência fonológica.

A razão disso parece resultar do fato de que, ao contrário do que ocorre em inglês, a aquisição da codificação fonológica é relativamente fácil em ortografias regulares ou consistentes. Com efeito, erros de decodificação são relativamente raros entre crianças que aprendem a ler nessas ortografias, até mesmo entre crianças com dificuldades de leitura. De modo geral, as dificuldades observadas, ou seja, leitura lenta e laboriosa, e presença de erros ortográficos (embora fonologicamente plausíveis) na escrita de palavras, parecem resultar de dificuldades na aquisição da codificação ortográfica. Diante dessa evidência, não é surpreendente que alguns estudiosos tenham sugerido que a nomeação seriada rápida contribua mais para a habilidade de leitura e escrita em ortografias regulares do que a consciência fonológica.

Embora alguns estudos tenham encontrado resultados condizentes com essa hipótese (e.g. de Jong \& van der Leij, 1999; Wimmer, Mayringer, \& Landerl, 2000), a evidência existente está longe de ser conclusiva. Por exemplo, Patel, Snowling e de Jong (2004) sugeriram que a associação relativamente modesta entre a consciência fonológica e a habilidade de leitura encontrada nesses estudos pode ter resultado de artefatos metodológicos. Em particular, esses pesquisadores sugeriram que os testes de consciência fonológica utilizados nesses estudos são relativamente fáceis e, como resultado, incapazes de detectar diferenças individuais importantes. Em consonância com essa sugestão, Patel et al. (2004) encontraram uma associação estreita entre uma medida mais difícil de consciência fonológica e medidas de acurácia e fluência de leitura, tanto entre crianças que estavam aprendendo a ler em inglês, quanto entre crianças que estavam aprendendo a ler em holandês, uma ortografia caracterizada por relações letra-som relativamente regulares. Por outro lado, a associação entre a nomeação seriada rápida e a habilidade de leitura foi surpreendentemente modesta. De fato, após Patel et al. (2004) haverem controlado o efeito de variações na idade, no vocabulário e na ortografia em que as crianças estavam aprendendo a ler, apenas a consciência fonológica continuou a contribuir significativamente para a habilidade de leitura.

Os resultados negativos obtidos por Patel et al. (2004) para a nomeação seriada rápida podem ter sido influenciados pelo fato de que apenas testes de nomeação de cores e figuras de objetos foram incluídos no seu estudo. Há evidência de que a nomeação seriada rápida de letras e/ou números correlaciona-se estreitamente com medi- 
das de habilidade de leitura em ortografias mais regulares (Bowers \& Wolf, 1993). É possível, no entanto, que essa associação possa ser explicada em função do fato de que, em ortografias regulares, a habilidade de leitura é normalmente avaliada através de testes de fluência de leitura de palavras, ou seja, testes que, como a tarefa de nomeação seriada rápida, requerem que o examinando responda o mais rapidamente possível. De fato, não é evidente que a nomeação seriada rápida contribua mais estreitamente do que a consciência fonológica para outras medidas importantes da competência alfabética nessas ortografias. Por exemplo, a julgar pelos resultados de estudos sobre a alfabetização em alemão (Moll, Fussenegger, Willburger, \& Landerl, 2009) e turco (Nikolopoulos, Goulandris, Hulme, \& Snowling, 2006), a consciência fonológica contribui tanto ou mais do que a nomeação seriada rápida para a habilidade de escrever palavras corretamente em ortografias regulares.

No presente estudo, a contribuição da consciência fonológica e da nomeação seriada rápida foi avaliada em uma amostra de jovens e adultos com pouca ou nenhuma escolaridade que estavam aprendendo a ler em português, uma ortografia que, como as ortografias alemã, holandesa e turca, é mais regular do que a inglesa. Tanto estímulos não-alfanuméricos quanto estímulos alfanuméricos foram utilizados para avaliar a habilidade de nomeação seriada rápida. Além disso, embora não tenhamos incluído medidas de fluência de leitura, o estudo incluiu testes de acurácia de leitura e escrita de palavras. É possível, portanto, que seus resultados contribuam para a nossa compreensão do papel desempenhado pela consciência fonológica e pela nomeação seriada rápida no processo de alfabetização em ortografias relativamente mais regulares do que a ortografia inglesa.

\section{Método}

Este trabalho é parte de um projeto maior, intitulado "Inteligência, processamento fonológico e habilidade de leitura e escrita de indivíduos em programas de alfabetização de adultos", aprovado pelo Comitê de Ética em Pesquisa com Seres Humanos da Universidade Federal de Minas Gerais (Processo no ${ }^{\circ}$ ETIC 141/05). Todos os participantes consentiram em participar do estudo por meio da assinatura de um Termo de Consentimento Livre e Esclarecido (TCLE), o qual foi lido em voz alta pelo examinador, na presença do professor alfabetizador.

\section{Participantes}

A amostra incluiu 72 jovens e adultos saudáveis, sem suspeita de retardo mental, matriculados em turmas iniciais de programas de alfabetização para jovens e adultos na cidade de Belo Horizonte, Minas Gerais. A idade dos participantes variava entre 16 e 81 anos $(M=53,87 ; D P$ $=14,90)$. Do total de participantes, 58 eram do sexo feminino e 14 do sexo masculino.

\section{Procedimentos e Instrumentos de Avaliação}

Os participantes foram avaliados individualmente, em uma sala reservada no próprio local onde estudavam, em sessões que duravam cerca de 15 minutos cada. Os participantes foram submetidos a testes que avaliavam as habilidades acadêmicas, a consciência fonológica e a nomeação seriada rápida.

Habilidades Acadêmicas. Leitura: a habilidade de ler palavras foi avaliada através do subteste de leitura do Teste de Desempenho Escolar (TDE; Stein, 1994). A tarefa do participante consistia em ler em voz alta uma lista composta de 70 palavras impressas em letras minúsculas em uma folha de papel.

Escrita: o subteste de escrita do TDE foi utilizado para avaliar a habilidade do indivíduo de escrever o seu nome e mais 34 palavras ditadas pelo examinador. A administração da tarefa seguiu as orientações contidas no manual do teste.

Matemática: diante da dificuldade dos participantes de definirem o seu grau de escolaridade, o subteste de matemática do TDE foi utilizado como uma medida aproximada do nível educacional. Nessa tarefa, os participantes eram solicitados a solucionar 35 operações aritméticas impressas em uma folha de papel.

Conhecimento do nome das letras: a tarefa do participante consistia em nomear as 23 das 26 letras do alfabeto, impressas em ordem aleatória em um único cartão. Apenas o conhecimento de letras maiúsculas foi avaliado. O coeficiente de confiabilidade (split-half) da tarefa na presente amostra foi de 0,91 .

Consciência Fonológica. Detecção de rima: a tarefa consistia de três itens de treinamento, seguidos de 31 itens experimentais. Para cada item, o participante era solicitado a identificar, entre três palavras distintas enunciadas em voz alta pelo examinador (e.g., dedo - bala - mala), as duas que rimavam. $\mathrm{O}$ coeficiente de confiabilidade da tarefa (split-half) foi de 0,81 .

Detecção de fonemas: a tarefa do participante consistia em identificar, entre três palavras diferentes enunciadas pelo examinador (e.g., doce - bola - dedo), as duas que começavam com o mesmo som. A tarefa era composta por três itens de treinamento e 20 itens experimentais. O coeficiente de confiabilidade da tarefa (split-half) foi de 0,79 .

Nomeação Seriada Rápida. O participante era instruído a nomear, o mais rapidamente possível, estímulos impressos em cartões individuais. Quatro cartões, cada um com um tipo de estímulo (cores, objetos, números ou letras) foram utilizados para avaliar essa habilidade. Cada cartão continha cinco estímulos diferentes (por exemplo, o cartão das letras continha as letras a, d, $\mathrm{o}, \mathrm{s}$, e p) apresentados 10 vezes cada um (totalizando 50 itens) em ordem aleatória e na forma de uma matriz composta por cinco linhas e 10 colunas. Para cada cartão, o escore consistia no tempo gasto para nomear os 50 estímulos. 
Corrêa, M. F. \& Cardoso-Martins, C. (2012). O Papel da Consciência Fonológica e da Nomeação Seriada Rápida na Alfabetização de Adultos.

\section{Resultados}

A Tabela 1 apresenta o número médio de respostas corretas, o desvio padrão e os escores mínimos e máximos para cada uma das tarefas administradas no estudo. Com exceção da tarefa de conhecimento do nome das letras, em que $80 \%$ dos participantes acertaram 21 ou mais das 23 letras avaliadas, a distribuição dos escores nas demais tarefas conformou-se à distribuição normal segundo o teste de Kolmogorov-Smirnov.

Tabela 1

Escore Médio, Desvio Padrão e Escores Máximo e Mínimo nas Diversas Tarefas Administradas

\begin{tabular}{lcccc}
\hline \multicolumn{1}{c}{ Medidas } & Média & $D P$ & Mínimo & Máximo \\
\hline Leitura (máx.=70) & 35,72 & 24,43 & 0 & 69 \\
Escrita (máx.=34) & 9,22 & 9,68 & 0 & 33 \\
Matemática (máx.= 35) & 9,65 & 4,62 & 3 & 20 \\
Nome das letras (máx.= 23) & 20,61 & 4,07 & 2 & 23 \\
Detecção de rima (máx.=31) & 22,82 & 5,62 & 7 & 31 \\
Detecção de fonema (máx.=20) & 13,43 & 4,05 & 4 & 20 \\
NSR: cores (tempo em segundos) & 54,20 & 17,91 & 31 & 146 \\
NSR: objetos (tempo em segundos) & 44,71 & 17,33 & 20 & 120 \\
NSR: letras (tempo em segundos) & 46,34 & 24,02 & 19 & 171 \\
NSR: números (tempo em segundos) & 41,42 & 14,73 & 20 & 103 \\
\end{tabular}

A Tabela 2 apresenta os resultados de correlação de Pearson entre as diversas medidas. Conforme ilustrado nessa tabela, as medidas de consciência fonológica e nomeação seriada rápida correlacionaram-se significativamente com a habilidade de leitura e escrita. O mesmo ocorreu para os testes de conhecimento do nome das letras e de matemática, os quais também correlacionaramse com as medidas de consciência fonológica e nomeação seriada rápida. Em vista desse padrão de correlações, análises de regressão foram realizadas com o intuito de controlar o efeito de diferenças no conhecimento do nome das letras e na matemática sobre a relação entre, por um lado, a consciência fonológica e a nomeação seriada rápida $\mathrm{e}$, por outro lado, a habilidade de leitura $\mathrm{e}$ escrita. Em todas essas análises, os escores nas tarefas de conhecimento do nome das letras e matemática entraram na equação nos dois primeiros passos, seguidos pelos escores nos testes de consciência fonológica ou nomeação seriada rápida. Tendo em vista a correlação entre as tarefas de detecção de rima e detecção de fonema e, como é de praxe na literatura, os escores nessas duas medidas foram combinados em um único escore de consciência fonológica. Esse escore correspondeu à média dos escores padronizados em cada uma das tarefas em questão. Do mesmo modo, uma medida composta para a nomeação seriada rápida de cores e objetos e uma para a nomeação seriada rápida de letras e números foram computadas. Uma vez que os escores no teste de conhecimento do nome das letras apresentaram uma distribuição assimétrica, essa variável foi transformada em uma variável dicotômica em função do valor da mediana, ou seja, os escores abaixo da mediana foram classificados como zero e os escores acima da mediana como um.

Tabela 2

Correlações de Pearson entre as Diversas Medidas Utilizadas no Estudo

\begin{tabular}{|c|c|c|c|c|c|c|c|c|c|}
\hline & 1 & 2 & 3 & 4 & 5 & 6 & 7 & 8 & 9 \\
\hline 1. Leitura & & & & & & & & & \\
\hline 2. Escrita & $0,82 * *$ & & & & & & & & \\
\hline 3. Matemática & $0,52 * *$ & $0,50 * *$ & & & & & & & \\
\hline 4. Nome das letras & $0,58 * *$ & $0,43 * *$ & $0,26^{*}$ & & & & & & \\
\hline 5. Rima & $0,56^{* *}$ & $0,53 * *$ & $0,42 * *$ & $0,64 * *$ & & & & & \\
\hline 6. Fonema & $0,47 * *$ & $0,49 * *$ & $0,31 * *$ & $0,49 * *$ & $0,60 * *$ & & & & \\
\hline 7. NSR cores & $-0,38 * *$ & $-0,30 * *$ & $-0,32 * *$ & $-0,44 * *$ & $-0,40 * *$ & $-0,36^{* *}$ & & & \\
\hline 8. NSR objetos & $-0,35 * *$ & $-0,26^{*}$ & $-0,35 * *$ & $-0,35 * *$ & $-0,25 * *$ & $-0,33 * *$ & $0,55^{* *}$ & & \\
\hline 9. NSR números & $-0,56 * *$ & $-0,47 * *$ & $-0,45 * *$ & $-0,54 * *$ & $-0,45 * *$ & $-0,40 * *$ & $0,55^{* *}$ & $0,79 * *$ & \\
\hline 10. NSR letras & $-0,63 * *$ & $-0,51 * *$ & $-0,46 * *$ & $-0,61 * *$ & $-0,46 * *$ & $-0,40 * *$ & $0,61 * *$ & $0,68 * *$ & $0,78 * *$ \\
\hline
\end{tabular}

$* p<0,05 ; * * p<0,01$. 
Tabela 3

A Contribuição da Consciência Fonológica e da Nomeação Seriada Rápida para a Habilidade de Leitura e Escrita

Variável Dependente

\begin{tabular}{|c|c|c|c|c|c|c|}
\hline \multirow[b]{2}{*}{$\begin{array}{l}\text { Variável } \\
\text { Independente }\end{array}$} & \multirow{2}{*}{\multicolumn{3}{|c|}{ Leitura }} & \multirow{2}{*}{\multicolumn{3}{|c|}{ Escrita }} \\
\hline & & & & & & \\
\hline \multicolumn{7}{|l|}{ Passos: } \\
\hline 1. Nome das letras & 0,55 & 0,29 & 0,00 & 0,61 & 0,38 & 0,00 \\
\hline 2. Matemática & 0,39 & 0,13 & 0,00 & 0,33 & 0,10 & 0,00 \\
\hline 3. Consciência fonológica & 0,33 & 0,08 & 0,00 & 0,28 & 0,06 & 0,00 \\
\hline 3. NSR: letras e números & $-0,39$ & 0,11 & 0,00 & $-0,22$ & 0,04 & 0,03 \\
\hline 3. NSR: cores e objetos & $-0,17$ & 0,02 & 0,05 & $-0,08$ & 0,01 & 0,39 \\
\hline 3. Consciência fonológica & 0,33 & 0,08 & 0,00 & 0,28 & 0,06 & 0,00 \\
\hline 4. NSR: letras e números & $-0,33$ & 0,07 & 0,00 & $-0,15$ & 0,01 & 0,16 \\
\hline 3. NSR: letras e números & $-0,39$ & 0,11 & 0,00 & $-0,22$ & 0,04 & 0,03 \\
\hline 4. Consciência fonológica & 0,22 & 0,03 & 0,02 & 0,24 & 0,04 & 0,02 \\
\hline
\end{tabular}

Nota. Sig. = nível de significância da mudança em $F$.

A Tabela 3 apresenta os resultados das análises de regressão. Como pode ser visto nesta tabela, tanto a consciência fonológica quanto a nomeação seriada rápida de letras e números continuaram a contribuir para a habilidade de leitura e escrita de palavras após o efeito de variações no conhecimento do nome das letras e no subteste de matemática do TDE ter sido controlado.

Com o objetivo de avaliar se a consciência fonológica e a nomeação seriada rápida de letras e números contribuem de maneira independente para a habilidade de leitura e escrita, duas análises adicionais de regressão foram realizadas para cada uma das variáveis dependentes. Como nas análises anteriores, os escores nas tarefas de conhecimento do nome das letras e matemática entraram na equação no primeiro e segundo passo, respectivamente. Em uma das análises, a consciência fonológica entrou na equação no terceiro passo e a nomeação seriada rápida de letras e números no quarto. Essa ordem foi invertida para a análise seguinte. Conforme ilustrado na parte inferior da Tabela 3, a consciência fonológica continuou a contribuir significativamente para a habilidade de leitura e escrita dos participantes. Por outro lado, embora a nomeação seriada rápida de letras e números tenha continuado a contribuir para a habilidade de leitura, ela não mais contribuiu para a habilidade de escrita após o controle do efeito de variações na consciência fonológica.

É possível, no entanto, que esses resultados tenham sido influenciados por peculiaridades da presente amostra. Por exemplo, os participantes incluídos no estudo possuíam pouca ou nenhuma escolarização e alguns mal sabiam ler ou escrever. É possível que a consciência fonológica desempenhe um papel mais importante nas fases iniciais da leitura, quando a criança ou o adulto está aprendendo a respeito das relações entre as letras e os sons e ainda não possui um vocabulário visual extenso (ver, de Jong \& van der Leij, 1999). Em vista disso, as análises de regressão foram refeitas incluindo apenas os participantes que leram 30 ou mais palavras no subteste de leitura do TDE $(N=44)$. Uma vez que a nomeação seriada rápida de cores e objetos não contribuiu para a habilidade de leitura e escrita nas análises anteriores, somente os escores para a nomeação seriada rápida de letras e dígitos foram utilizados. Os resultados dessas análises aparecem na Tabela 4. Nem a consciência fonológica, nem a nomeação seriada rápida contribuíram para as variações na habilidade de leitura dos leitores mais competentes. No entanto, a consciência fonológica explicou uma porção significativa das variações na habilidade de escrita, mesmo após o controle do efeito de variações no conhecimento das letras, na matemática e na nomeação seriada rápida. O mesmo não ocorreu para a nomeação seriada rápida.

\section{Discussão}

O presente estudo teve como objetivo principal avaliar a contribuição da consciência fonológica e da nomeação seriada rápida para a habilidade de leitura e escrita de jovens e adultos brasileiros com baixa escolaridade. $\mathrm{O}$ estudo foi correlacional e incluiu 72 jovens e adultos inscritos em programas de alfabetização tardia.

Os resultados questionam a hipótese de que, em ortografias caracterizadas por relações letra-som relativamente regulares ou consistentes, a nomeação seriada rápida contribui mais do que a consciência fonológica para as habilidades de leitura e escrita. Embora a nomeação seriada rápida de letras e dígitos tenha explicado uma 
Corrêa, M. F. \& Cardoso-Martins, C. (2012). O Papel da Consciência Fonológica e da Nomeação Seriada Rápida na Alfabetização de Adultos.

Tabela 4

A Contribuição da Consciência Fonológica e da Nomeação Seriada Rápida de Letras e Números para a Habilidade de Leitura e Escrita dos Leitores Mais Competentes

Variável Independente

Variável Dependente

\begin{tabular}{llllll}
\hline \multicolumn{3}{l}{ Leitura } & \multicolumn{3}{c}{ Escrita } \\
$\beta$ & Mudança em $\mathrm{R}^{2}$ & Sig. & $\beta$ & Mudança em $\mathrm{R}^{2}$ & Sig. \\
\hline
\end{tabular}

Passos:

\begin{tabular}{lcccrrr} 
1. Nome das letras & 0,40 & 0,16 & 0,00 & 0,55 & 0,31 & 0,00 \\
2. Matemática & 0,12 & 0,01 & 0,43 & 0,15 & 0,02 & 0,27 \\
3. Consciência fonológica & 0,05 & 0,00 & 0,72 & 0,29 & 0,08 & 0,03 \\
4. NSR: letras e números & 0,03 & 0,00 & 0,85 & $-0,14$ & 0,01 & 0,33 \\
& & & & & & \\
3. NSR: letras e números & 0,01 & 0,00 & 0,94 & $-0,22$ & 0,03 & 0,13 \\
4. Consciência fonológica & 0,06 & 0,00 & 0,69 & 0,28 & 0,06 & 0,04 \\
\hline
\end{tabular}

Nota. Sig. = nível de significância da mudança em $F$.

porção significativa das variações na habilidade de leitura dos participantes, mesmo após o controle do efeito de variações na consciência fonológica, o mesmo não ocorreu para a escrita. A consciência fonológica, por sua vez, contribuiu de maneira significativa e independente tanto para a habilidade de leitura quanto para a habilidade de escrita dos participantes. Resultados semelhantes foram encontrados em uma análise que incluiu apenas os leitores mais competentes.

Os resultados do presente estudo também lançam luz sobre a hipótese de que a nomeação seriada rápida é particularmente importante para a aquisição da codificação ortográfica. É razoável supor que, até mesmo em ortografias caracterizadas por relações letra-som consistentes, a habilidade de escrever palavras corretamente pressuponha a habilidade de codificação ortográfica. A razão disso é que, mesmo nessas ortografias, é comum um mesmo som ser representado por letras ou grafemas diferentes, independentemente do contexto em que ele aparece na pronúncia da palavra (e.g., a representação do som / $\int$ / nas palavras bicho e lixo). Na medida em que a relação entre a nomeação seriada rápida e a alfabetização é mediada pela aquisição da habilidade de codificação ortográfica, a nomeação seriada rápida deveria contribuir para a habilidade de escrever palavras, independentemente de variações na consciência fonológica. No presente estudo, contudo, a nomeação seriada rápida não mais contribuiu para a habilidade de escrever palavras após o efeito de variações na consciência fonológica haver sido controlado. Por outro lado, a consciência fonológica continuou a contribuir para aquela habilidade após termos controlado o efeito de variações na nomeação seriada rápida de letras e números. Esses resultados confirmam os resultados de outros estudos envolvendo crianças aprendendo a ler em ortografias relativamente mais regulares do que a ortografia inglesa (e.g., Moll et al., 2009; Nikolopoulos et al., 2006) e sugerem que a consciência fonológica contribui tanto para a aquisição da codificação fonológica quanto para a aquisição da codificação ortográfica. Outros estudos são, no entanto, necessários para explorar melhor a hipótese de que a nomeação seriada rápida contribui para a habilidade de codificação ortográfica. No presente estudo, a habilidade de escrita dos participantes foi avaliada pelo TDE, um teste cujos itens não são balanceados pela frequência de ocorrência na língua ou regularidade das relações letrasom. Estudos que incluam medidas mais puras do conhecimento ortográfico são necessários para avaliar melhor essa questão.

Em síntese, os resultados do presente estudo questionam a hipótese de que, em ortografias relativamente mais regulares do que a ortografia inglesa, a nomeação seriada rápida desempenha um papel mais importante do que a consciência fonológica. É verdade que a ortografia portuguesa, embora mais consistente do que a ortografia inglesa, é menos consistente do que as ortografias alemã, holandesa e turca. Contudo, é pouco provável que essa peculiaridade possa explicar as diferenças entre os nossos resultados e os resultados de estudos conduzidos com crianças aprendendo a ler naquelas ortografias. Conforme observamos anteriormente, estudos recentes sugerem que a consciência fonológica é um correlato da habilidade de leitura e escrita tão ou mais importante do que a nomeação seriada rápida, independentemente da natureza mais ou menos regular da ortografia (Ziegler et al., 2010).

As implicações educacionais dos resultados desse estudo são óbvias. Tendo em vista o envolvimento da consciência fonológica nos processos de leitura e escrita, é possível que o treinamento dessa habilidade contribua, de certa maneira, para a eficácia dos programas de alfabetização de jovens e adultos. Segundo o Ministério da Educação (2010), a despeito dos investimentos do gover- 
no federal, os programas de alfabetização de jovens e adultos no Brasil registram alto índice de evasão e absenteísmo, além de fraco desempenho e baixa taxa de aprendizagem. Os resultados do presente estudo sugerem que o treinamento da consciência fonológica poderá contribuir para a aquisição da leitura e da escrita nessa população e, dessa forma, diminuir o alto índice de fracasso dos programas de alfabetização de adultos.

\section{Referências}

Babayigit, S., \& Stainthorp, R. (2011). Modeling the relationships between cognitive-linguistic skills and literacy skills: New insights from a transparent orthography. Journal of Educational Psychology, 103(1), 169-189.

Binder, K., \& Borecki, C. (2008). The use of phonological, orthographic, and contextual information during reading: A comparison of adults who are learning to read and skilled adult readers. Reading and Writing, 21, 843-858.

Bowers, P. G., \& Wolf, M. (1993). Theoretical links among naming speed, precise timing mechanisms and orthographic skill in dyslexia. Reading and Writing, 5(1), 69-85.

Bryant, P., \& Bradley, L. (1987). Problemas de leitura na criança. Porto Alegre, RS: Artes Médicas.

Caravolas, M., Volin, J., \& Hulme, C. (2005). Phoneme awareness is a key component of alphabetic literacy skills in consistent and inconsistent orthographies: Evidence from Czech and English children. Journal of Experimental Child Psychology, 92(2), 107-139.

Cardoso-Martins, C. (1995). Consciência fonológica e alfabetização. Rio de Janeiro, RJ: Vozes.

Cardoso-Martins, C., \& Pennington, B. F. (2004). The relationship between phoneme awareness and rapid serial naming and literacy acquisition: The role of developmental period and reading ability. Scientific Studies of Reading, 8(1), 27-52.

Castles, A., \& Coltheart, M. (2004). Is there a causal link from phonological awareness to success in learning to read? Cognition, 91, 77-111.

de Jong, P. F., \& van der Leij, A. (1999). Specific contributions of phonological abilities to early reading acquisition: Results from a Dutch latent variable longitudinal study. Journal of Educational Psychology, 91, 450-476.

Durgunoglu, A. Y., \& Öney, B. (2002). Phonological awareness in literacy acquisition: It's not only for children. Scientific Studies of Reading, 6(3), 245-266.

Loureiro, C. S., Braga, L. W., Souza, L. N., Nunes Filho, G., Queiroz, E., \& Dellatolas, G. (2004). Degree of illiteracy and phonological and metaphonological skills in unschooled adults. Brain and Language, 89, 499-502.

Lukatela, K., Carello, C., Shankweiler, D., \& Liberman, I. Y. (1995). Phonological awareness in illiterates: Observations from Servo-Croatian. Applied Psycholinguistics, 16, 463-487.

Manis, F., Doi, L., \& Bhadha, B. (2000). Naming speed, phonological awareness, and orthographic knowledge in second graders. Journal of Learning Disabilities, 33, 325-333.

Mellard, D. F., Fall, E., \& Woods, K. L. (2010). A path analysis of reading comprehension for adults with low literacy. Journal of Learning Disabilities, 43(2), 154-165.

Ministério da Educação. (2010). Relatório de avaliação do plano plurianual 2008-2011. Brasília, DF.

Moll, K., Fussenegger, B., Willburger, E., \& Landerl, K. (2009). RAN is not a measure of orthographic processing: Evidence from the asymmetric German orthography. Scientific Studies of Reading, 13(1), 1-25.
Morais, J., Cary, L., Alegria, J., \& Bertelson, P. (1979). Does awareness of speech as a sequence of phones arise spontaneously? Cognition, 7, 323-331.

Mota, M. M. E. P., \& Castro, N. R. (2007). Alfabetização e consciência metalingüística: Um estudo com adultos não alfabetizados. Estudos de Psicologia (Campinas), 24(2), 169179.

Nikolopoulos, D., Goulandris, N., Hulme, C., \& Snowling, M. J. (2006). The cognitive bases of learning to read and spell in Greek: Evidence from a longitudinal study. Journal of Experimental Child Psychology, 94(1), 1-17.

Patel, T. K., Snowling, M. J., \& de Jong, P. F. (2004). A crosslinguistic comparison of children learning to read in English and Dutch. Journal of Educational Psychology, 96(4), 785797.

Powell, D., Stainthorp, R., Stuart, M., Garwood, H., \& Quinlan, P. (2007). An experimental comparison between rival theories of rapid automatized naming performance and its relationship to reading. Journal of Experimental Child Psychology, 98, 46-68.

Stein, L. M. (1994). TDE: Teste de Desempenho Escolar: Manual para aplicação e interpretação. São Paulo, SP: Casa do Psicólogo.

Torgesen, J., Wagner, R., Rashotte, C., Burgess, S., \& Hecht, S. (1997). Contributions of phonological awareness and rapid automatic naming ability to the growth of word-reading skills in second - to fifth - grade children. Scientific Studies of Reading, 1, 161-185.

Wagner, R. K., \& Torgesen, J. K. (1987). The nature of phonological processing and its causal role in the acquisition of reading skills. Psychological Bulletin, 101(2), 192-212.

Wagner, R., Torgesen, J., Laughon, P., Simmons, K., \& Rashotte, C. (1993). Development of young readers' phonological processing abilities. Journal of Educational Psychology, 85, 83-103.

Wimmer, H. (1993). Characteristics of developmental dyslexia in a regular writing system. Applied Psycholinguistics, 14, $1-33$.

Wimmer, H., \& Mayringer, H. (2002). Dysfluent reading in the absence of spelling difficulties: A specific disability in regular orthographies. Journal of Educational Psychology, 94, 272-277.

Wimmer, H., Mayringer, H., \& Landerl, K. (2000). The doubledeficit hypothesis and difficulties in learning to read a regular orthography. Journal of Educational Psychology, 92, 668-680.

Wolf, M., \& Bowers, P. (1999). The double-deficit hypothesis for the developmental dyslexias. Journal of Educational Psychology, 91, 415-438.

Ziegler, J. C., Bertrand, D., Toth, D., Csepe, V., Reis, A., Faisca, L., et al. (2010). Orthographic depth and its impact on universal predictors of reading: A cross-language investigation. Psychological Science, 21(4), 551-559. 